\title{
Karyomorphology and Evolution in Italian Populations of Three Neottieae Species (Orchidaceae)
}

\author{
Saverio D'Emerico ${ }^{1, *}$, Domenico Pignone ${ }^{2}$ and Antonio Scrugli ${ }^{3}$ \\ ${ }^{1}$ Dipartimento di Biologia e Patologia vegetale, Sezione di Biologia Vegetale (ex Istituto Botanico), \\ Via Orabona, 4, Università di Bari, I-70125 Bari, Italy \\ ${ }^{2} \mathrm{CNR}$, Istituto del Germoplasma, Bari, Italy \\ ${ }^{3}$ Dipartimento di Scienze Botaniche, Università di Cagliari, Cagliari, Italy
}

Accepted March 7, 2000

\begin{abstract}
Summary A karyological analysis on Italian populations of 3 species, belonging to the genera Cephalanthera and Listera (Orchidaceae: Neottieae tribe) and characterized by asymmetrical karyotypes, was undertaken. Karyomorphological and C-banding data strongly suggest that in 2 species, namely $C$. damasonium and $L$. cordata, chromosomal rearrangements involving the large and medium-large chromosomes constituted the principal mechanism of chromosome evolution. This process is particularly evident in $L$. cordata, where karyotype evolution occurred by means of centric fission along with an increase in chromosome number and in the overall chromosomal heterochromatin content. Altogether the present observation on Italian specimens of the Neottieae corroborate previous proposals of a central role of Robertsonian rearrangements and quantitative heterochromatin variation in karyotype reorganization.
\end{abstract}

Key words Orchidaceae, Neottieae, Cephalanthera, Listera, Feulgen staining, Giemsa C-banding, Karyotype evolution.

Extensive information on chromosome number and karyotype morphology is available for Neottieae species (Kliphuis 1963, Meili-Frei 1966, Mehra and Kashyap 1983). The Neottieae generally possess a characteristic kind of asymmetrical chromosomal complement in which chromosome lengths have an uneven distribution and chromosomes form two groups of different size: such a karyotype is named bimodal. Stebbins (1971) proposed that bimodality is best regarded as an extreme and specialized form of karyotype asymmetry, which originates from a combination of centric fission, pericentric inversions and unequal translocations.

In the tribe Neottieae, C-banding has been described for only few species of the genera Cephalanthera, Epipactis and Limodorum (Schwarzacher and Schweizer 1982, D'Emerico et al. 1999). These studies revealed that the investigated species were characterized by different amounts of heterochromatin, principally located in the chromosomes of the large group.

Evidence exists that alterations in the amount of heterochromatin can be induced by structural rearrangements (Bernard and Miklos 1979). Centric fusion has been inferred in Cephalanthera, also based on the observation of «quadruple structures» in the centromeric regions (Schwarzacher and Schweizer 1982). In Epipactis, centric mutations appear to be indicated also by the presence of many chromosomes with heterochromatic short arms, which could result from centric fission of chromosomes followed by heterochromatin amplification. Moreover, in E. tremolsii, E. distans and E. microphylla a distinctive distribution of bands around the centromere, resembling the «quadruple structure» as in Cephalanthera, has been observed (D'Emerico et al. 1999). Finally, recent karyotype analysis in Phragmipedium and Paphiopedilum (Orchidaceae: Cypripedioideae tribe) have revealed chromosome alterations generated by Robertsonian fission (Cox et al. 1998). The present paper reports on the karyotype morphology and distribution of heterochromatin in Italian speci-

\footnotetext{
* Corresponding author, e-mail: demerico@botanica.uniba.it
} 
Table 1. Neottieae taxa investigated, number of individuals studied, origin of samples, chromosome number, karyotype formula and (in brackets) total length

\begin{tabular}{|c|c|c|c|c|}
\hline Taxon & $\begin{array}{l}\text { Number of } \\
\text { individuals }\end{array}$ & Provenance & $2 n$ & $\begin{array}{l}\text { Karyotype formula } \\
\text { and length }(\mu \mathrm{m})\end{array}$ \\
\hline \multicolumn{5}{|l|}{ Cephalanthera } \\
\hline \multirow[t]{2}{*}{ C. damasonium } & 8 & Sardinia: S'Astaria (Meana sardo) & 36 & $18 m+8 s m+8 s t+2 t[60.33]$ \\
\hline & 7 & Sardinia: Perdasdefogu (Nuoro) & 36 & $12 \mathrm{~m}+12 \mathrm{sm}+8 \mathrm{st}+4 \mathrm{t}[63.00]$ \\
\hline \multicolumn{5}{|l|}{ Listera } \\
\hline \multirow[t]{2}{*}{ L. ovata } & 6 & Basilicata: Muro Lucano (Potenza) & 34 & $2 \mathrm{M}+18 \mathrm{~m}+12 \mathrm{sm}+2 \mathrm{st}^{\mathrm{s}}[67.66]$ \\
\hline & 5 & Sardinia: Riu Bau Onu (Laconi) & 34 & $2 \mathrm{M}+18 \mathrm{~m}+12 \mathrm{sm}+2 \mathrm{st}^{\mathrm{s}}[67.66]$ \\
\hline L. cordata & 5 & Trentino: Dolomiti (Trento) & 38 & $12 \mathrm{M}+14 \mathrm{~m}+4 \mathrm{sm}+2 \mathrm{st}+6 \mathrm{t}[69.00]$ \\
\hline
\end{tabular}

mens of the genera Cephalanthera and Listera.

\section{Materials and methods}

Samples are listed in Table 1. Mitotic and meiotic chromosomes were observed in tissues of immature ovaries. These were pre-treated with $0.3 \%$ colchicine at room temperature for $2 \mathrm{~h}$. For Feulgen staining they were fixed for $5 \mathrm{~min}$ in a $5: 1: 1: 1$ (volume ratio) mixture of absolute ethanol, chloroform, glacial acetic acid, and formalin (Battaglia 1957a). Hydrolysis was made at $20 \pm 2^{\circ} \mathrm{C}$ in $5.5 \mathrm{~N} \mathrm{HCl}$ for $20 \mathrm{~min}$ (Battaglia 1957b). The material was then stained in freshly prepared Feulgen stain.

For C-banding, immature ovaries were fixed in ethanol-glacial acetic acid $(3: 1 \mathrm{v} / \mathrm{v})$ and stored at $-18^{\circ} \mathrm{C}$ for one day to several months. Subsequently, they were squashed in $45 \%$ acetic acid, coverslips were removed by the dry ice method and the preparations air-dried overnight. Slides were then immersed in $0.2 \mathrm{~N} \mathrm{HCl}$ at $60^{\circ} \mathrm{C}$ for $3 \mathrm{~min}$, thoroughly rinsed in distilled water and then treated with $4 \% \mathrm{Ba}(\mathrm{OH})_{2}$ at $20^{\circ} \mathrm{C}$ for $4 \mathrm{~min}$. After very thorough rinsing they were incubated in $2 \times \mathrm{SSC}$ at $60^{\circ} \mathrm{C}$ for $1 \mathrm{~h}$, and stained in 3-4\% Giemsa (BDH) at $\mathrm{pH} 7$.

Chromosome pairs were identified and arranged on the basis of chromosome length. The nomenclature used for describing karyotype composition followed Levan et al. (1964).

\section{Results}

Cephalanthera damasonium (Miller) Druce. The chromosome number observed in all individuals from different localities was $2 n=36$ in agreement with Fedorov (1969). This species possesses a bimodal karyotype consisting of three large and fifteen small chromosome pairs. In specimens from Sardinia, collected at Perdasdefogu and S'Astaria, 2 different cytotypes could be identified (Table 1). The former showed telocentric chromosome pairs 1 and 2, while pair 3 was subtelocentric. C-banding evidenced that the short arm of chromosome pair 1 was completely heterochromatic while the short arm of chromosome pair 2 was partially heterochromatic with euchromatic telomeric region. Pairs 3 and 5 showed a C-band on the short arm proximally to the centromere. Many chromosomes showed centromeric heterochromatin (Figs. 1b, 2a, 3e). The latter cytotype showed a modified karyotype in which chromosome pair 1 was telocentric, pair 2 subtelocentric, and pair 3 submetacentric. This distinct karyotype of $C$. damasonium has never been previously reported. Staining with the C-banding technique showed that the short arm of chromosome pair 1 was completely heterochromatic, the short arm of pair 2 euchromatic, while the short arm of chromosome pair 3 was completely heterochromatic, but with a lesser staining intensity. Many pairs of the small chromosomes group showed the presence of centromeric heterochromatin (Figs. 1a, 2b, 3c). 

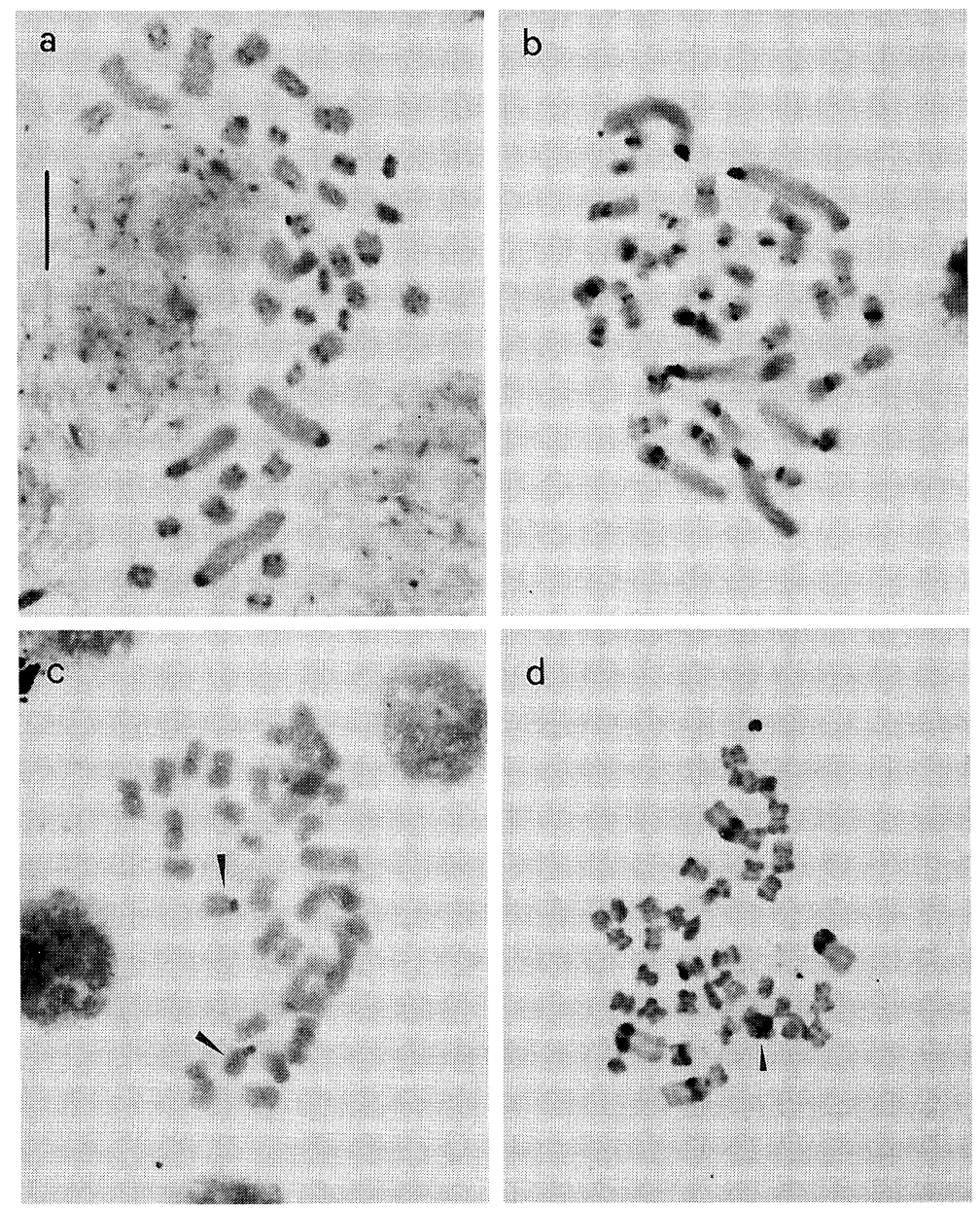

Fig. 1. Giemsa C-banded somatic metaphases of: a) Cephalanthera damasonium, $2 \mathrm{n}=36$, from S'Astaria (Sardinia), b) C. damasonium, $2 \mathrm{n}=36$, from Perdasdefogu (Sardinia), c) Listera ovata, $2 \mathrm{n}=34$, with heterochromatic pair arrowed, d) $L$. cordata, $2 \mathrm{n}=38$; the arrow indicates two chromosomes. Bar: $10 \mu \mathrm{m}$.

Listera ovata (L.) R. Br. ex Aiton fil. The observed chromosome number of $2 n=34$ in all individuals from different localities, coincides with previously reported data (Kliphuis 1963, Meili-Frei 1966, Scrugli 1980), moreover examination of metaphase I in embryo sac mother cells revealed 17 bivalents. Some authors reported different chromosome numbers, i.e. $2 \mathrm{n}=32,34,35,36,38,40$ and 42 (Kliphuis 1963, Meili-Frei 1966), the number 2n=34 being the most frequent. Additionally, B chromosomes are reported to be present (Garbari 1971, Vosa and Barlow 1972, Vosa 1983). This species has a karyotype consisting of one metacentric M, 9 metacentric $\mathrm{m}, 6$ submetacentric and one subtelocentric satellited pairs (chromosome pair 9). Chromosome pairs 1-3 are long; pairs 4-17 are shorter and resemble to each other. None of the chromosomes showed clear centromeric bands; heterochromatin, however, was clearly present in the short arm and the satellite region of chromosome pair 9 (Figs. 1c, 4a).

Listera cordata (L.) R. Br. in Aiton fil. showed $2 \mathrm{n}=38$ chromosomes in agreement with previous reports (Kliphuis 1963, Meili-Frei 1966). Also $2 n=36$ and 42 chromosomes have been observed (Mehra and Kashyap 1983). Additionally, in this study it was also possible to count $2 n=39$ chromosomes. This number probably is the result of handling, during which chromosomes occasionally brake at the secondary constriction. This species had a karyotype consisting of 6 metacen- 


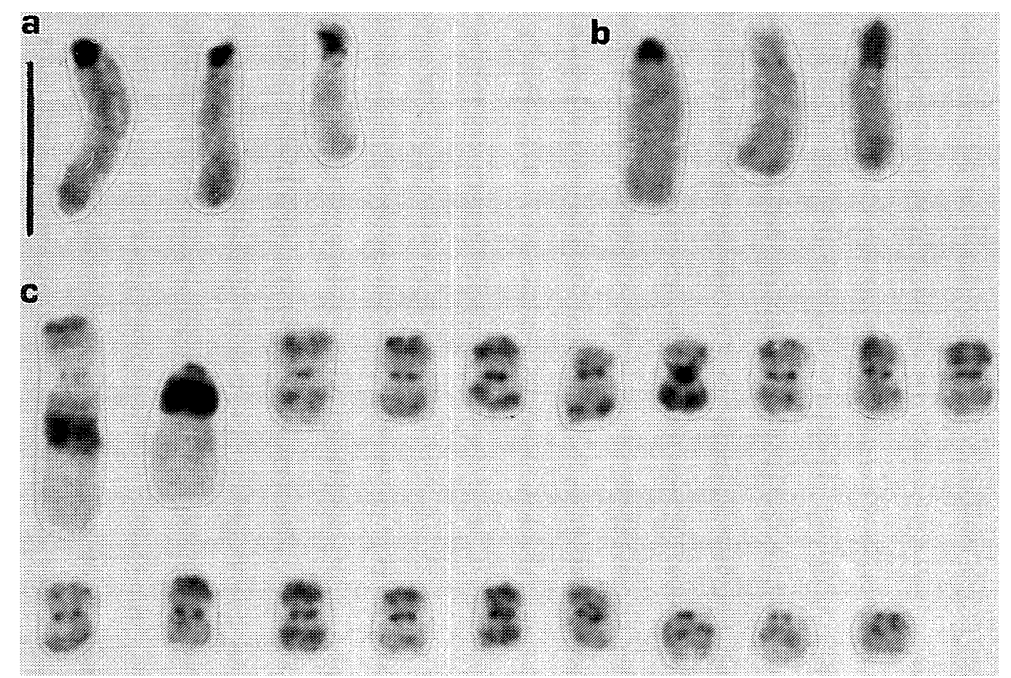

Fig. 2. C-banded chromosomes of: a) Cephalanthera damasonium from Perdasdefogu (haploid set of marker chromosomes), b) C. damasonium from S'Astaria (haploid set of marker chromosomes), to note pair 3 with the short arm weakly positively C-banded, c) Listera cordata, haploid set. Bar: $10 \mu \mathrm{m}$.

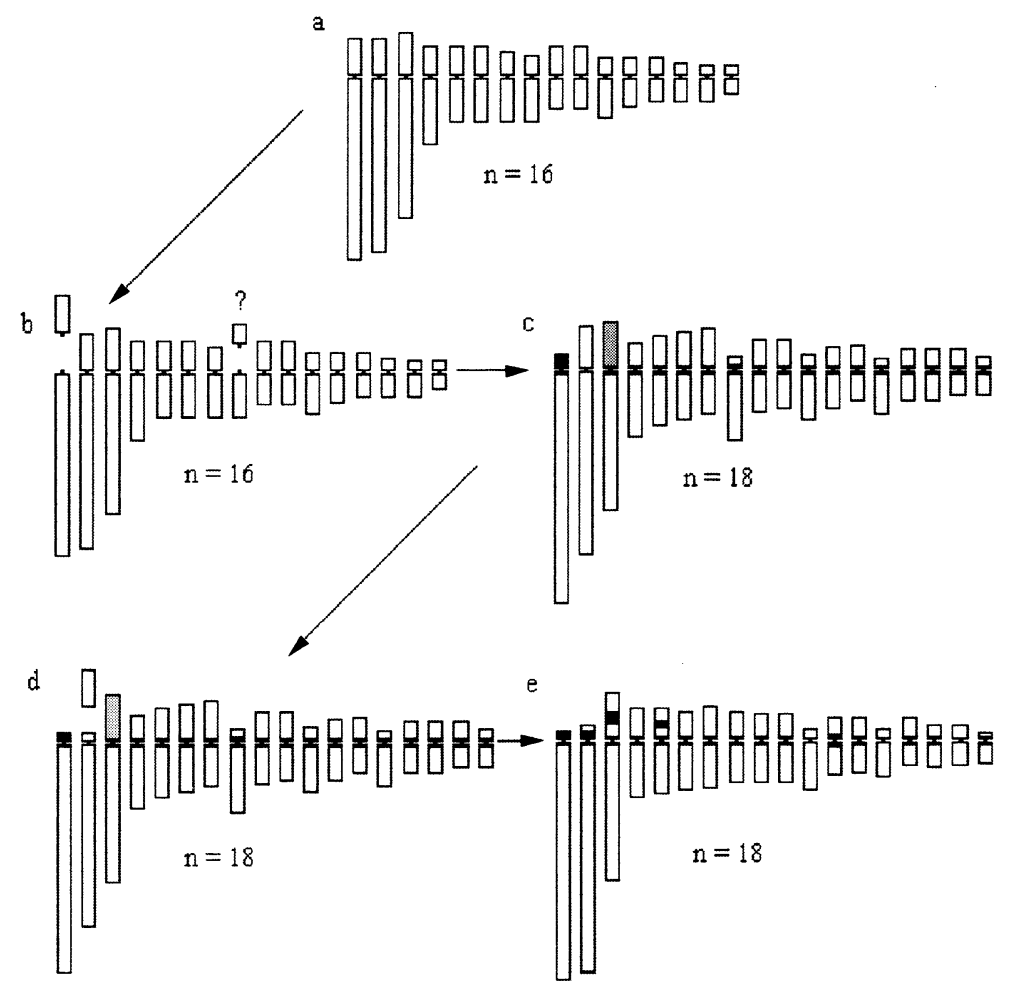

Fig. 3. Hypothetical karyotype evolution in Cephalanthera damasonium: a) haploid idiogram of a possible ancestral karyotype, $2 n=32$, b) centromeric fission of pair 1 and of a not identified metacentric or submetacentric chromosome, c) cytotype from S'Astaria, $2 \mathrm{n}=36$, d) modification of pair 2 by deletion and/or translocation, e) haploid idiogram of the most commonly observed cytotype (Perdasdefogu and mainland Italy). 
tric M, 7 metacentric $\mathrm{m}, 2$ submetacentric, one subtelocentric and 3 telocentric pairs. Pair 1 and 2 are long, pairs 3-19 show gradually decreasing length. All chromosomes had centromeric C-bands, with pair 7 showing a larger centromeric band. Many chromosomes revealed terminal C-bands in one (pairs 1, 3, 5, $7,12,13,14$ ) or, rarely, in both arms (pair 15). Intercalary C-bands were present in the short arms of pairs 1, 4, 5 and 10, and the long arm of pairs 1, 3, 6, 13, 17, 18, and 19. Pairs 1 and 2 showed a large proximal heterochromatin band in the long arm (Figs. 1d, 2c, 4b).

\section{Discussion}

In many plant taxa, modification of chromosomes structure is frequently due to Robertsonian rearrangements (Stebbins 1971, Jones 1978, Marks 1983), even though it has been proposed that the significance of this event is confined (Jones 1998). In our studies, chromosomal restructurations this kind have been observed in some species of Orchidaceae, tribe Neottieae.

Robertsonian mutations to explain the origin of the Cephalanthera damasonium karyotype were first suggested by Schwarzacher and Schweizer (1982). Using Feulgen staining and C-banding, they proposed that an ancestral karyotype with $2 n=32$ chromosomes could be transformed, by means of centric fission and heterochromatin amplification in pairs 1 and 2, into a restructured karyotype with $2 n=36$ chromosomes possessing characteristic telocentric pair 1 and subtelocentric pair 2.

In the present study we found that two cytotypes of $C$. damasonium coexist in Sardinia, one of which, from Perdasdefogu, is similar to that distributed in Italian peninsula (D'Emerico et al. 1999), even though some differences could be found in band sizes. The S'Astaria karyotype from Sardinia differs in some key features regarding both chromosome morphology and C-band distribution. Pairs 2 and 3, in fact, show a clear differentiation in chromosome structure and location of constitutive heterochromatin. In this case, the geographical isolation in Sardinia may be responsible for the differentiation into and/or the maintenance of two different cytotypes. It is interesting to note that the clear difference in karyotypes is not paralleled by significant morphological differences of the populations.

If the observed differences in karyomorphology and C-band distribution are interpreted in the light of the hypothesis of Schwarzacher and Schweizer (1982), it can be assumed that the karyotype of the S'Astaria specimens is less derived than the Perdasdefogu and mainland karyotypes or has reverted towards an original morphology. In addition, based on the Schwarzacher and Schweizer (1982) hypothesis, one could associate the origin of $2 n=36$ with the emergence of two long telocentric chromosomes. On the contrary, our data suggest that the number $2 n=36$ arose from a possible $2 n=32$ ancestral karyotype by centromeric fission of pair 1 and a not identified metacentric or submetacentric chromosome. Subsequently, the modification of pair 2 by deletion and/or translocation resulted in the cytotype commonly found in Perdasdefogu (Sardinia) and mainland Italy.

The observed karyotype differentiation associated to geographical gradients in Sardinia may be interpreted as an evidence of the evolutionary pressure that has acted on the species. In addition 
to the sensitivity of most Orchids to environmental changes, as a consequence of their breeding system, karyomorphological variation in Orchids species could be proposed as a biodiversity indicator in a given environment.

Of the 2 species of Listera studied, the only ones present in Europe, L. ovata had $2 \mathrm{n}=34$ chromosomes, whereas $L$. cordata $2 \mathrm{n}=38$. The karyomorphology of the both species could suggest that the karyotype of $L$. cordata retain a strong affinity to the chromosomal set of $L$. ovata, although it differs from the latter for the presence of four telocentric chromosomes pairs. It can be hypothesized that in L. cordata, centric fission, occurred in the second long pair and in one medium-sized chromosome pair of an ancestral karyotype, might have resulted in a karyotype from which the present days $L$. cordata derives.

In the present C-banding analysis, $L$. ovata and $L$. cordata showed considerable differences in the amount and distribution of heterochromatin. In the former species heterochromatin appeared restricted to a small region of satellited chromosome pair 9, while in L. cordata many chromosomes showed a high number of heterochromatin bands. The observed C-banding distribution in L. cordata might be interpreted as the indication of a recent karyotype reorganization, an association between increase of heterochromatin with evolution indicators has, in fact, been pointed out in other Orchids (Stergianou 1989, Vij 1989, D’Emerico et al. 1996).

\section{Acknowledgements}

The authors thank Prof. Paolo Grünanger, University of Pavia, Italy, for providing plants of Listera cordata. This research was supported by a grant from the Ministry of the University and Research and Technological Science (M.U.R.S.T. 60\%).

\section{References}

Battaglia, E. 1957a. A new "5 minutes-fixation" using cold hydrolysis. Caryologia 9: 368-370.

— 1957b. A simplified Feulgen method using cold hydrolysis. Caryologia 9: 372-373.

Bernard, J. and Miklos, G. L. G. 1979. Functional aspects of satellite DNA and heterochromatin. Intern. Rev. Cytology 58: $1-14$.

Cox, V. A., Abdelnour, J. G., Bennett, D. M. and Leitch, J. I. 1998. Genome size and karyotype evolution in the slipper orchids (Cypripedioideae: Orchidaceae). Amer. J. Bot. 85: 681-687.

D’Emerico, S., Grünanger, P., Scrugli, A. and Pignone, D. 1999. Karyomorphological parameters and C-bands distribution suggest phyletic relationship within the subtribe Limodorinae Bentham (Orchidaceae). Pl. Syst. Evol. 217: 147-161.

-, Pignone, P. and Bianco, P. 1996. Karyomorphological analyses and heterochromatin characteristic disclose phyletic relationships among $2 n=32$ and $2 n=36$ species of Orchis (Orchidaceae). Pl. Syst. Evol. 200: 111-124.

Fedorov, A. A. 1969. Chromosome numbers of flowering plants. 459. Leningrad, Akademija Nauk SSSR.

Garbari, F. 1971. B-Chromosomes in Listera ovata (L.) R. Br. (Orchidaceae). Preliminary observations in Italian populations. Inform. Bot. Ital. 3: 216-221.

Jones, K. 1978. Aspects of chromosome evolution in higher plants. Adv. Bot. Res. 6: 119-194.

- 1998. Robertsonian fusion and centric fission in karyotype evolution of higher plants. Bot. Rev. 64: 273-289.

Kliphuis, E. 1963. Cytological observations in relations to the taxonomy of the orchids of the Netherlands. Acta Bot. Neerl. 12: $172-194$.

Levan, A., Fredga, K. and Sandberg, A. A. 1964. Nomenclature for centromeric position on chromosomes. Hereditas 52: 201-220.

Marks, G. E. 1983. Evidence for the Occurrence of Dispensable and Disadvantageous Chromatin. In: Brandham, P. E. and Bennett, M. D. (eds.). Kew Chromosome Conf. II. Allen and Unwin. London. pp. 269-272.

Mehra, P. N. and Kashyap, S. K. 1983. Cytological studies in some west Himalayan orchids. Tribe: Necttieae. I. Subtribe: Limodorinae. Caryologia 36: 33-45.

Meili-Frei, E. 1966. Cytogenetik und Cytotaxonomie einheimischer Arten von Epipactis, Listera, Neottia (Orchidaceae). Ber. Schweiz. Bot. Ges. 75: 219-292.

Schwarzacher, T. and Schweizer, D. 1982. Karyotype analysis and heterochromatin differentiation with Giemsa C-banding 
and fluorescent counterstaining in Cephalanthera (Orchidaceae). Pl. Syst. Evol. 141: 91-113.

Scrugli, A. 1980. Numeri cromosomici per la Flora Italiana. Inform. Bot. Ital. 12: 149-151.

Stebbins, G. L. 1971. Chromosomal Evolution in Higher Plants. Arnold. London.

Stergianou, K. K. 1989. Habit differentiation and chromosome evolution in Pleione (Orchidaceae). Pl. Syst. Evol. 166: 253-264.

Vij, S. P. 1989. Chromosomes and speciation in Indian orchids. J. Orchid Soc. India. 3: 11-24.

Vosa, C. G. 1983. The ecology of B-chromosomes in Listera ovata (L.) R. Br. (Orchidaceae). Caryologia 36: 113-120.

- and Barlow, P. W. 1972. Meiosis and B-chromosomes in Listera ovata (Orchidaceae). Caryologia 25: 1-8. 